\title{
Uncertainty estimate of flood hazard for an extreme flood
}

\author{
André Paquier ${ }^{1, a}$ \\ ${ }^{1}$ UR RiverLy, INRAE, 5, rue de la Doua,69625 Villeurbanne, France
}

\begin{abstract}
Hydrodynamic models are usually calibrated from historical events observations and then used for estimating the flood hazard for more extreme floods. In such a case, the uncertainty related to the calibration process is likely to be emphasized by the inadequacy of the model to describe hydraulic processes met during the flooding of additional areas. Comparing the results of various 1D and 2D models of the Besançon flooding by Doubs river for a 10,000 years return period, an estimate of the resulting uncertainty on both water depth and flow velocity is carried out. A difference of more than one metre is found for peak water levels and can be related to the features of the hydraulic models. However, this latter difference is smaller than the uncertainty range linked to the estimate of the peak discharge even if a detailed hydrological study is performed such as during the Flowres ("Predicting the flow in the floodplains with evolving land occupations during extreme flood events") project. Some conclusions are linked to the specific case of Besançon (e.g. the effect of the loop of Doubs river) but other ones are more general (e.g. representation of the urban pattern).
\end{abstract}

\section{Introduction}

According to the European Flood Directive (European Union, 2007), the flood hazard should be accurately assessed in high-risk areas over the river floodplains, during extreme flood events. However, the prediction of the very high flows is not an easy task due to the lack of field data (Neal et al., 2015) and to the strong link between flow resistance and the land use of the floodplain. With increasing return period of the flood, the heterogeneity of the hydraulic roughness elements (e.g. trees, houses) strongly vary. The physical processes are complex, still largely unexplored, and the assumptions linked to numerical modelling cannot be validated without field data.

The Flowres ("Predicting the flow in the floodplains with evolving land occupations during extreme flood events") project (https://flowres.inrae.fr/en/) aims at improving the flood hazard assessment in floodplains in investigating in laboratory the hydrodynamic structure associated with extreme flood flows and in assessing if the existing numerical modeling practices that calibrate models on frequent floods are reliable for extreme floods. Experimental results proved the interest of using the ISM method (Proust et al., 2009) for compound channels flows and of representing flow resistance using drag coefficients in addition to Manning Strickler bed friction (Dupuis et al., 2016). Some numerical models were applied to simulate the floods of the Doubs river at Besançon. Uncertainties related to the hydrological computation of discharges and to the computation of the hydraulic flood hazard were compared.

${ }^{a}$ Corresponding author: andre.paquier@inrae.fr

DOI 10.3311/FLOODRisk2020.3.1
The paper presents some of the results of this latter study. Then, the paper is organized as follows. A first paragraph describes the Besançon field case. A second part details the data used and the principles for designing the various models. In a third part, the various results are compared with observations on the calibration 1910 flood and finally, one provides a range of uncertainty for the extreme floods.

\section{Presentation of Besançon floods}

In 1910, high rainfalls hit the whole Northern France. These latter rainfalls generate the flooding of Paris in the Seine River Basin and up to now, the 1910 flood is the reference flood for Paris. In the city of Besançon located on the River Doubs, the 1910 flood was also an important event and remains one of the reference floods. However, there is still a discussion about the causes of the flood that damaged the whole centre of the city (Boudou, 2015).

The flood carried out a lot of wood logs (from a paper mill) that were blocked against the piles of the bridges crossing the river inside the town of Besançon. This process was particularly marked upstream the bridges (Figure 1) "pont de la République" (North of the city centre) and "pont Battant" (West of the city centre) because of the arches of the bridges. Then, the head losses between the upstream and downstream sections of the bridges were increased. Another cause of high damages was the failure of the protection system. The city of Besançon was a fortified city but, in the nineteenth century, the walls previously used for war purposes were 
transformed to flood defences closing all the openings at flood times. During the 1910 flood, these closures were not as efficient as planned and particularly, upstream from the bridge "Pont Battant", some panels broke and the flow suddenly invaded the streets of the city centre.

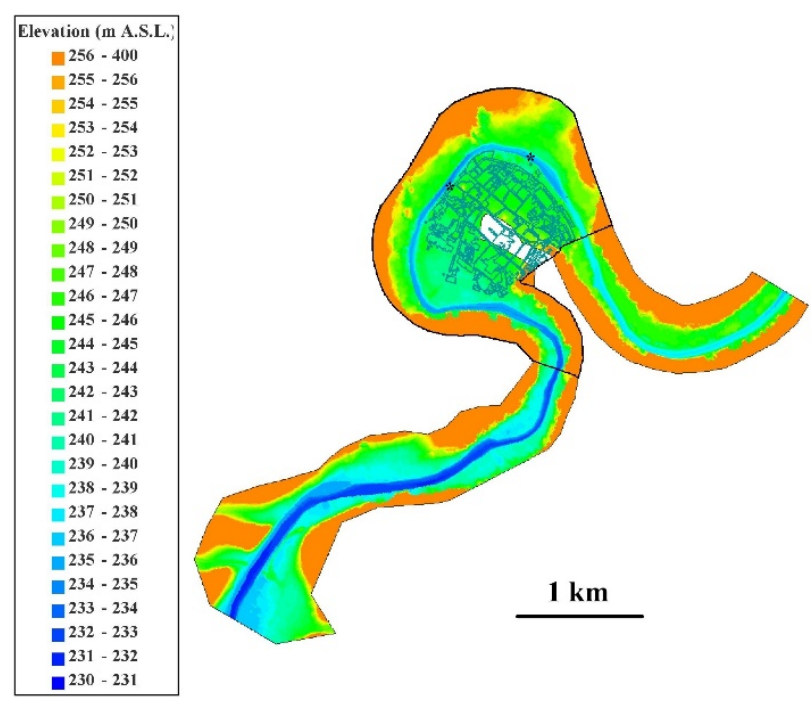

Figure 1. Topography of the studied area. The black lines are the limits of the 2D area. The grey lines are the limits of buildings in the city centre. The stars are the locations of "pont de la République" and "Pont Battant".

Because floods are still a threat to Besançon, it is still worthwhile understanding the flooding processes during the 1910 flood and estimating the relative influence of the various random events that might occur during flood periods. More than 40 marks along the river and inside the city recall the water elevation at peak flow. Thus, the 1910 flood that produced the higher flooded area in Besançon can be used for model calibration.

The studied area (Figure 1) is a 10 kilometres long sector along the Doubs river. The city centre is concentrated inside a loop of the river and the urban pattern has not changed a lot since 1910. From a hydraulic point of view, the more important changes are the construction of reconstruction of some bridges across Doubs river and the urbanization of the right bank of the river.

\section{Presentation of the models}

\subsection{Software}

During the Flowres project, various software was used. For modelling the Besançon floods, software from Université Catholique de Louvain La Neuve (UCL) and INRAE were used. Only results using INRAE software are shown because the 2D software from UCL provided very similar results and the conclusion was that the selection of software is not a cause of uncertainty if the selected equations are the same ones and the stability of the numerical method is ensured.

INRAE used the 1D software Rubar 3 (El kadi et al., 2008) and the 2D software Rubar 20 (El kadi et al., 2009) as well as the model coupling the two latter ones (Paquier and Bazin, 2013). They solve shallow water equations using an explicit second order numerical scheme. Stability is ensured if the Courant number is below 1, which means that time step is very short if space step is very small.

\subsection{Available data}

All the data used in this study come from the local authorities of Besançon (either "Département" or "Région"). For the topography, one can distinguish three levels of definition:

- 25 cross section profiles of the Doubs main channel set along the ten kilometres of the river present in the longer models;

- 4800 points located in the flood plain inside the city boundaries (average distance between points: about $30 \mathrm{~m}$ ). Although these latter points are not regularly spaced, they provide the elevation with accuracy at key locations;

- a basic D.E.M. (digital elevation model) with a regular spacing of 81 metres in $\mathrm{x}$ and $\mathrm{y}$ directions. Less accurate than the two previous sets of data, this latter D.E.M. is used to complete the bed elevation.

To build the hydraulic models, additional data concern the hydraulic structures on the river (three weirs and eight bridges), a profile along the top of the walls protecting the city from the river flood and the limits of the buildings coming from an urban database. These latter limits were not used directly but the buildings were gathered into blocks and the limits of the blocks were used only in the city centre and only for some models. Note also that all the calculations are carried out with the models built to represent the 1910 situation, which means with the present bed elevation (assuming that only slight changes occurred) but with the hydraulic structures of 1910 .

In order to characterize the 1910 flood, the discharge flow hydrograph (5 days with a peak flow of $1656 \mathrm{~m}^{3} / \mathrm{s}$ ) was assessed by a hydrological study that determines also the extreme floods. In order to obtain a reliable assessment of the peak flow discharge, the classical (Agregee method) study of the gauging station at Besançon (over the period 1910-2014) was doubled by a study using the Schadex method (Lang et al., 2014) based on a regional analysis of rainfall on 12 stations (period 1958 to 2012) over the whole basin. Synthetic flood hydrographs were produced for the return periods $\mathrm{T}$ of 10, 100, 1000 and 10000 years. The peak flow discharges were respectively 1134,1741 , 2473 and $3282 \mathrm{~m}^{3} / \mathrm{s}$. The uncertainty range for the extreme discharges ( $\mathrm{T}=1000$ or 10000 years) is about $20 \%$, which means a 10,000 years peak discharge between 2600 and $4000 \mathrm{~m}^{3} / \mathrm{s}$ ).

For 1910, a synthesis of the observations of peak water depths contains the limit of the flooded area of the city centre and a list of more than 40 flood marks, either along the river or inside the city centre.

\subsection{Building the models}

In order to estimate the uncertainty range, several hydraulic models were built (Paquier and Chiaverini, 2017). The first ones are 1D models built on cross sections of the main channel and the flood plain, one with a space 
step of about $100 \mathrm{~m}$ (usual calculation with cross sections of less than 100 points) and one with a space step of about $8 \mathrm{~m}$ (between cross sections and between points in a cross section) These models cannot define the flooding process inside the city centre accurately because, for high discharges, the flow crosses the city centre using shorter paths along the streets of the city. Thus, 2D models are also needed. One of these models is built from the same nodes as the 1D model at $8 \mathrm{~m}$ space step and contains about 213,000 cells. The other one uses another mesh that follows the layout of the main streets; thus, this model permits to identify the places that are occupied by (blocks of) buildings (Figure 2). By modifying the parameters of this latter model, four model variants can be derived:

- the base model (or "with closed buildings") in which the limits of the buildings (and of the historical walls) are represented by solid boundaries (no flow can cross them);

- the model with opened buildings in which some openings (doors, windows) are represented by orifices in order to be filled progressively;

the model without buildings in which the solid boundaries of the buildings disappear;

the model without buildings and walls in which also the historical walls disappear.

(Paquier et al., 2019) showed the sensitivity of the flood parameters to such parameters.

This 2D model is limited to the town centre and, because the smaller space step is about one third of the width of a street (Figure 2), it contains only 40,000 cells.

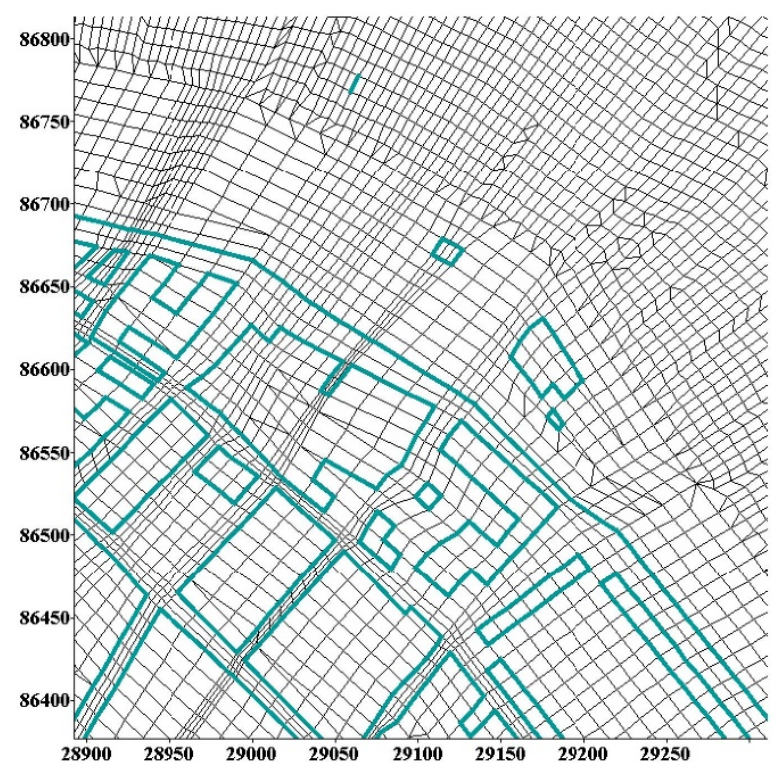

Figure 2. Zoom on the 2D mesh. Limits of the buildings and the walls are grey lines. Coordinates are in metres.

Finally, in order to represent the whole studied area, the part of this 2D model concerning the city centre is coupled with a 1D model of the main channel and the remaining flood plain. Results of this model are not analysed here below because this coupled model does not permit to save computational time and it is difficult to calibrate, part of the right flood plain being outside the protection of the historical walls
The upstream boundary of all the models is the flow hydrograph of the Doubs river at Besançon station. The downstream boundary for the 1D model was set to uniform flow, which perhaps means that the $1.5 \mathrm{~km}$ of the river downstream the third weir is not accurately calculated. For the $2 \mathrm{D}$ models, the rating curve corresponding to the $1 \mathrm{D}$ uniform flow is used.

\section{Results of the calculations}

\subsection{Calibration on the 1910 flood}

The calibration process starts with the 1D models and a first set of friction (Strickler) coefficients: $15 \mathrm{~m}^{1 / 3} \cdot \mathrm{s}^{-1}$ for the flood plain and $30 \mathrm{~m}^{1 / 3} \cdot \mathrm{s}^{-1}$ for the main channel. The first result is the similar peak water elevations obtained by the two 1D models, which permits us to continue with the simpler 1D model. In this simpler model (indicated here below "1D model"), an additional head loss was introduced adding a drag coefficient for the areas in which a high density of trees (respectively houses) is present. The mean parameters are a density of one tree of diameter equal to $0.3 \mathrm{~m}$ every 10 metres (resp. one house of $10 \mathrm{~m}$ every 30 metres or a block of houses of 90 m every 100 metres if dense urban pattern), a drag coefficient of 1.2 (resp. 1.3). This additional head loss has nearly no influence on the peak water depths. Then, because, in the real event, due to the blockage of wood logs against the Pont Battant, the head losses seem concentrated at this latter structure, the cross section is reduced at that location in order to obtain a local head loss slightly below one metre (Figure 3). Finally, the Strickler coefficients of the floodplain are modified to a value of $25 \mathrm{~m}^{1 / 3} \cdot \mathrm{s}^{-1}$ while those of the main channel are increased to $40 \mathrm{~m}^{1 / 3} \cdot \mathrm{s}^{-1}$ (and locally, around a weir, $80 \mathrm{~m}^{1 / 3} \cdot \mathrm{s}^{-1}$ ) along the city centre downstream the Pont Battant.

First the 2D calculations are performed with the same set of friction coefficients as the 1D model: $15 \mathrm{~m}^{1 / 3} \cdot \mathrm{s}^{-1}$ for the flood plain and $30 \mathrm{~m}^{1 / 3} \cdot \mathrm{s}^{-1}$ for the main channel. The $1 \mathrm{D}$ and the 2D models with the same nodes and the same friction coefficients provide different results; while 2D peak water elevations are generally higher, it is not the case downstream Pont Battant; the cause is perhaps the different distributions of the flow between the flood plain and the main channel. The finer 2D model and the 2D model without buildings and walls provide close peak water elevations, which permits us to continue calibration only with the 2D model of the city centre. As for the 1D model, the singular head loss is increased at the Pont Battant reducing the cross section of the main channel. Finally, the 2D Strickler coefficients are fixed at $50 \mathrm{~m}^{1 / 3} \cdot \mathrm{s}^{-}$ 1 in the main channel, $25 \mathrm{~m}^{1 / 3} \cdot \mathrm{s}^{-1}$ in the urbanized areas and $40 \mathrm{~m}^{1 / 3} \cdot \mathrm{s}^{-1}$ in the southern part of the loop in which parks are dominating. Depending of the type of 2D model, the peak water elevation along the main channel is quite different (Figure 3). However, looking at the flood marks inside the city centre (Figure 4), the conclusions are not exactly the same ones although the model with closed buildings provides the higher elevations and the larger flood extent (Figure 5). 


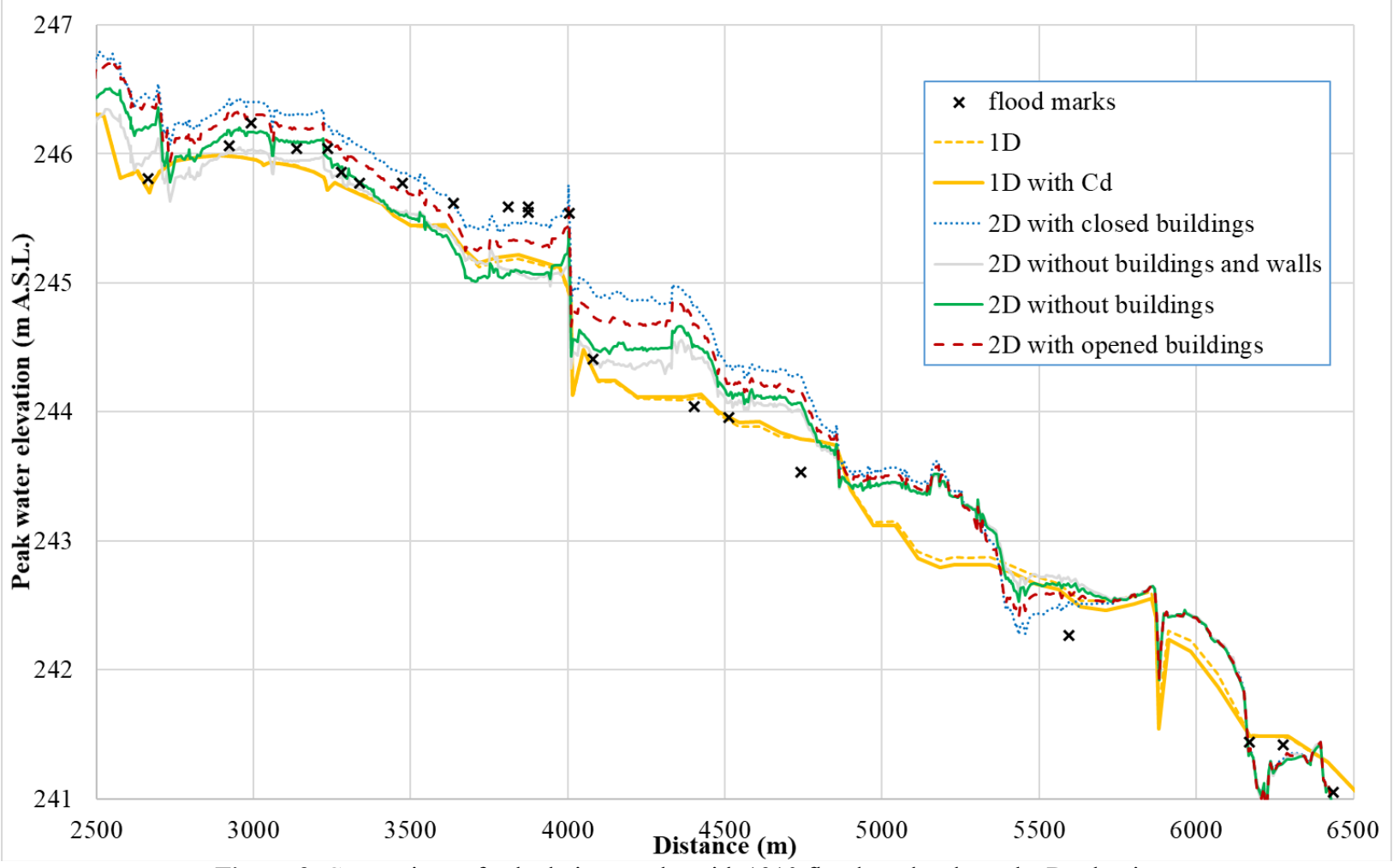

Figure 3. Comparison of calculation results with 1910 flood marks along the Doubs river

Figure 3 shows that finally the $1 \mathrm{D}$ and the 2D models have a quite different behaviour along the main channel, particularly downstream Pont Battant (distance over 4000). For both models, one cannot reduce the discrepancy between observations and calculation results because the blockage at the bridge was temporary, which is not introduced in the models. Even, if the reduction of the cross section at Pont Battant is the same in topography in the 1D and 2D models, the difference of velocity and flow path between the two models introduces different behaviours. However, the 2D model without buildings and walls (situation of the 1D model) is closer to the 1D model than the other 2D models and seems calibrated more accurately. Oppositely, Figure 5 shows that the 2D model with closed buildings provides a better estimate of the flood extent downstream. Then, because one cannot reduce the discrepancy between observations and calculation results, calibration cannot go further and the same friction coefficients are kept for all the 2D models.

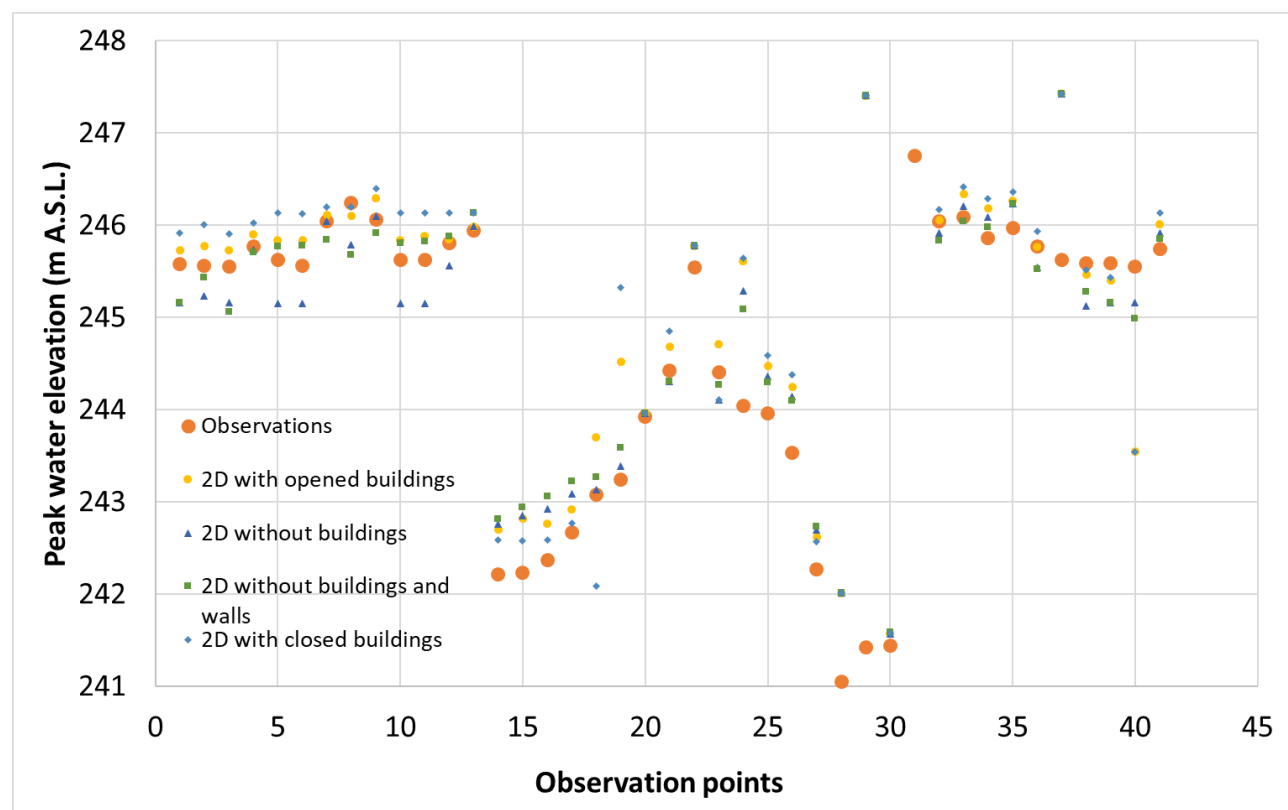

Figure 4. Comparison of 2D calculation results with 1910 flood marks inside Besançon city 


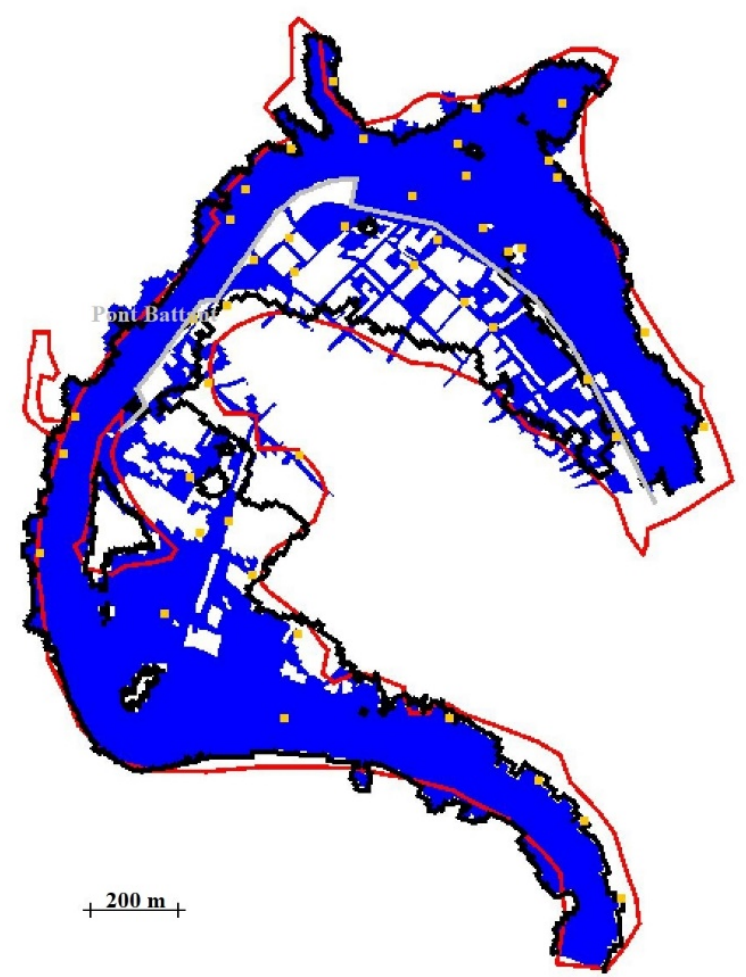

Figure 5. Comparison of 2D calculation results with observed flood extent inside Besançon city. Blue area is the extent of 2D calculation with closed buildings. The black line is the limit of the flooded area calculated without buildings but with the walls (in grey line). The red line is the limit from observations. The squares are the locations of the flood marks.

\subsection{Extreme floods}

Then, the 1D and 2D models calibrated on the 1910 flood are used for the extreme floods of return periods of 1,000 and 10,000 years. First, Figure 6 shows that the uncertainty range on the peak discharge is converted into a range of uncertainty of about $1.5 \mathrm{~m}$ (nearly 2 metres for the 2D model with closed buildings).

Second, Figure 7 shows that differences between models resulting from the calibration on the 1910 flood are slightly enhanced but this process is not uniform through the models. Because a larger part of the flow passes though the forests and the urban areas, the 1D model with $\mathrm{Cd}$ (additional head losses) shows higher peak water elevations in some sectors. Two groups of 2D models can be identified: with and without buildings. The difference of peak water elevations between the two groups is increasing with the flow discharge while it is the opposite inside each group. The 2D models without buildings provide results lower than 1D model upstream Pont Battant and higher downstream; a strong part of the additional flow (between 1910 and $\mathrm{T}=10000$ years) passes inside the city centre in the 2D model thus with a shorter flow path. With buildings, the resistance is much higher and provides peak water elevation up to $1 \mathrm{~m}$ higher.

Figure 8 confirms these results in terms of flood extent. The comparison of the flood extents between Figures 8 and 9 shows that the hydrological uncertainty range of flood extent is also twice as high as the difference between hydraulic models upstream Pont Battant.

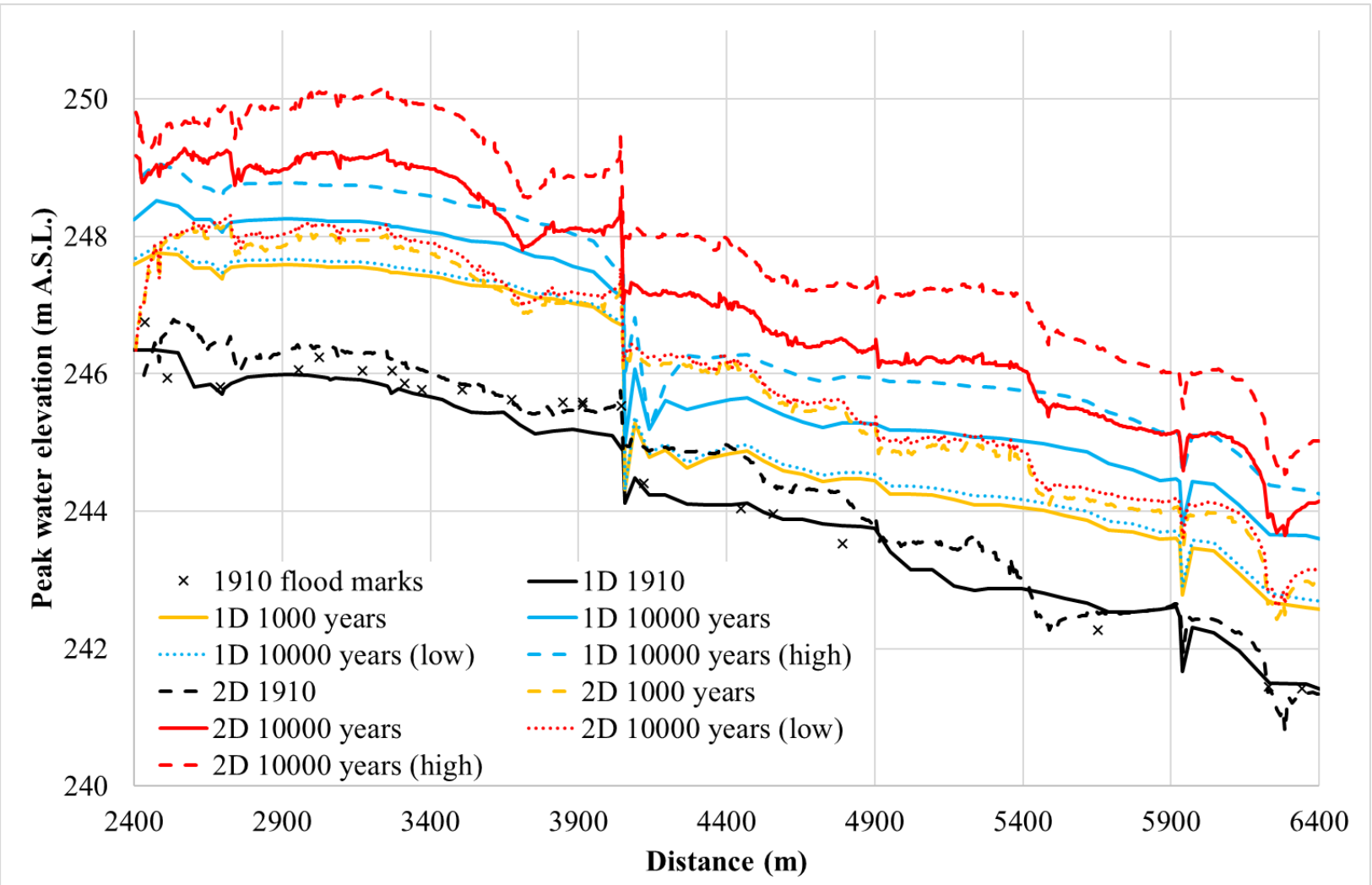

Figure 6. Calculation results for various return periods (usual 1D and 2D with closed buildings). Low and high lines are calculated using the low and high estimates of the 10,000 years return period discharge hydrographs.

\footnotetext{
a Corresponding author: andre.paquier@inrae.fr 


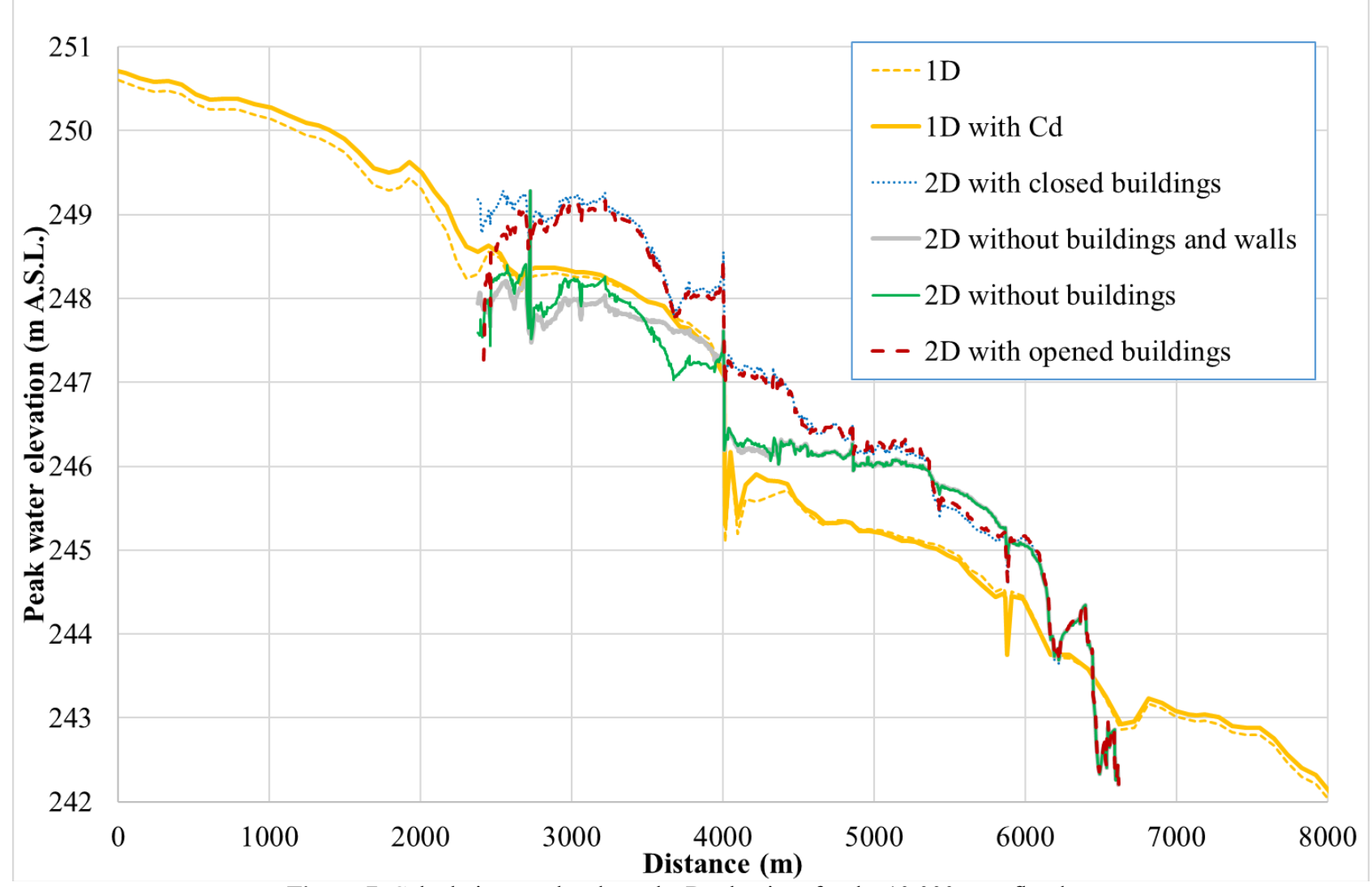

Figure 7. Calculation results along the Doubs river for the 10,000 year flood

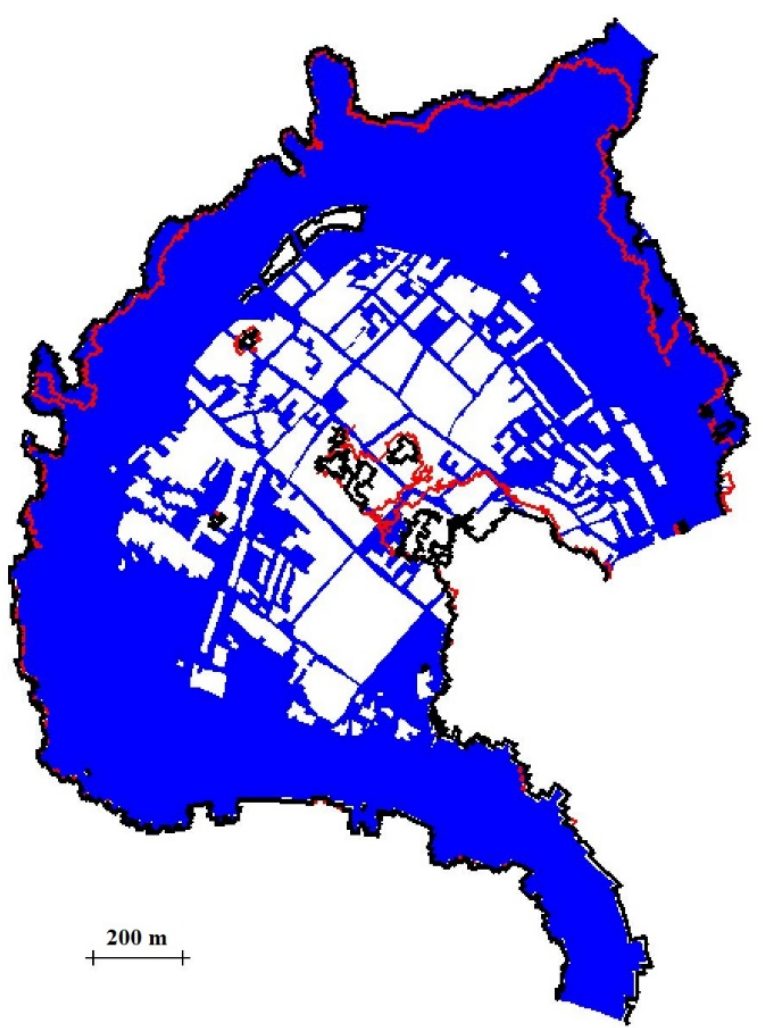

Figure 8. 2D calculation results for the 10,000 year flood extent. Red line is the limit for the calculation without walls and buildings, black line is the limit for the calculation with opened buildings.

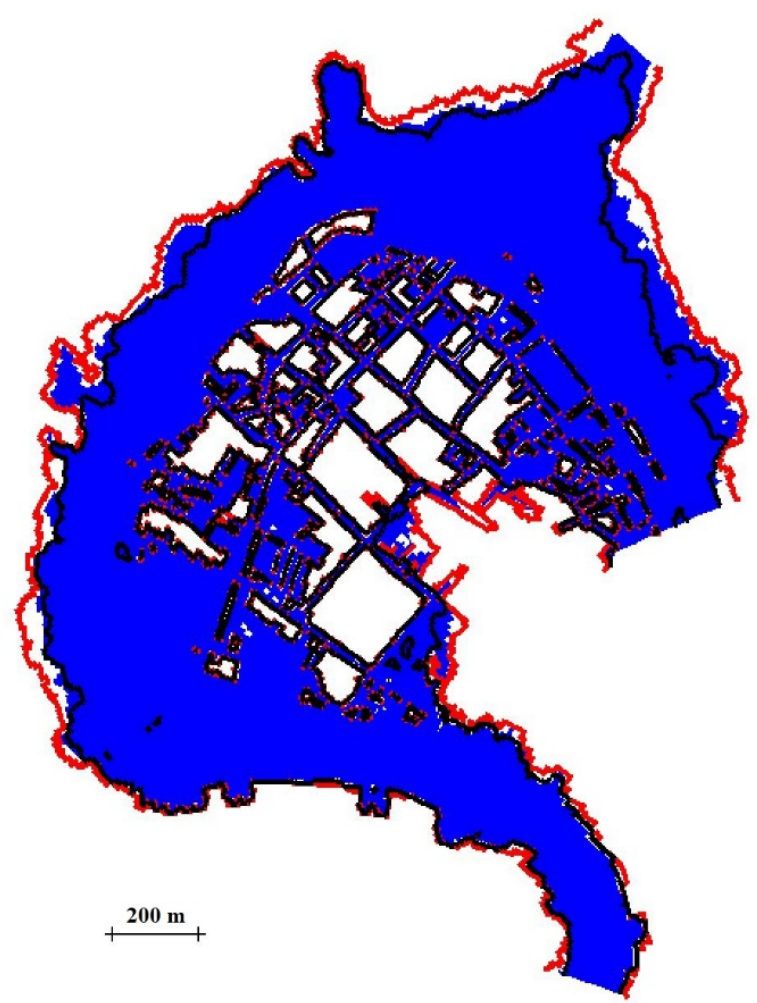

Figure 9. Hydrological range of uncertainty for the 10,000 years flood extent (2D calculation with closed buildings). Red line is the limit for the upper flow discharge, black line is the limit for the lower flow discharge. 


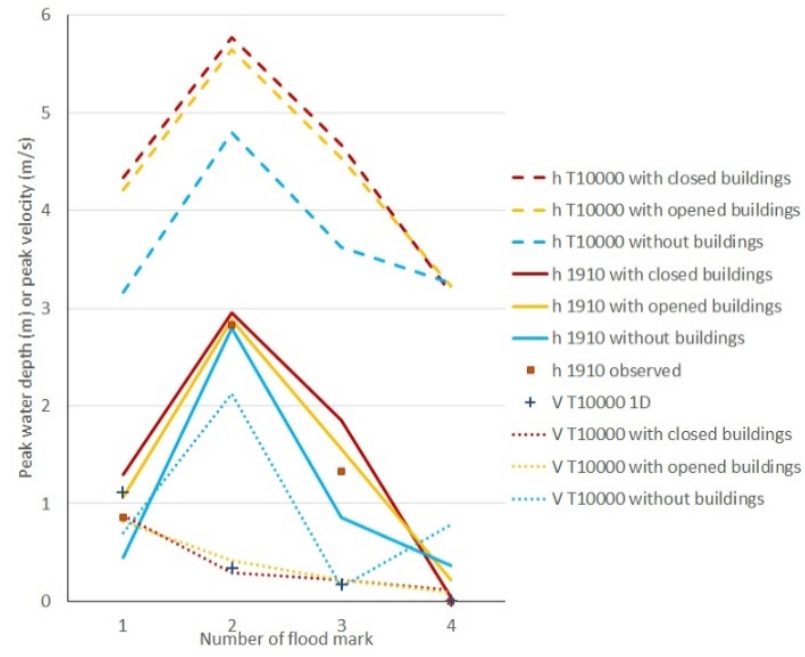

Figure 10. Comparison of peak water depth and peak velocity at four locations for the 10,000 years return period flood.

Note that the lower differences between hydraulic models downstream Pont Battant is a bias because they use the same downstream rating curve (thus a similar discharge provides the same water elevation).

For extreme floods, flood hazard should include also flow velocity that may become very high. Figure 10 shows the results for the 10,000 years flood on four points in which the water depth is quite well simulated by the models for the 1910 flood. Oppositely to water depth, the 1D velocity seems different from the $2 \mathrm{D}$ model without buildings (up to $80 \%$ of difference) and agrees quite well with the 2D models with buildings. Although the results vary from the location of the point, one should integrate that flood hazard (mainly velocity) inside a city centre depends a lot of the urban pattern. In order to reduce uncertainty, the DEUFI project (https://riverhydraulics.inrae.fr/en/projects/ongoingproject/anr-project-deufi-detailing-urban-flood-impact/) is focusing on the variations of the flood hazard inside the streets and the buildings.

\section{Conclusions}

For the 1910 flood, the water elevation along the River Doubs can be modelled either using a 1D model or a 2D model. The appropriate calibration of the head losses at the various structures is essential and more important than a detailed calibration of the friction coefficients. Inside the city centre, the flow pattern is conveniently described only if the blocks of buildings are introduced in the modelling, which permits to concentrate the flow in the streets. As observed in 1910, the failure of the flood defence walls influences the local flow pattern and may generate high velocity in one street facing the opening in the wall.

For an extreme flood (e.g. $T=10000$ years), the $\pm 20 \%$ uncertainty provides a difference of peak water depths of about $1.5 \mathrm{~m}$ much higher than the differences between various hydraulic models (about $1 \mathrm{~m}$ ) even if the calibration on the 1910 flood was difficult. If a 2D model is used, the buildings should be integrated into the modelling process in order to estimate the flow velocities in the streets. The effect of the openings in the blocks seems to decrease while the flow depth increases. If a 1D model is used, buildings (and trees) can be represented by an additional head loss calculated from an average drag force but this effect cannot be easily calibrated from the observation of ordinary floods.

\section{Acknowledgements}

This work has been supported by the French National Research Agency (ANR) under the grants ANR-14-CE030010 (FlowRes Project) and ANR-18-CE01-0020 (DEUFI Project). The author would like to thank Martin Boudou who provided data about the 1910 flood, Michel Lang who carried out the hydrological analysis of the floods and the staff of the Universite Catholique de Louvain La Neuve who performed alternative 2D calculations of the Besançon floods.

\section{References}

1. Boudou, M. (2015). A multidisciplinary approach for characterizing remarkable flood events: lessons from nine events in France (1910-2010). PhD thesis, Université Paul Valéry, Montpellier, France (in French).

2. Dupuis, V., Proust, S., Berni, C., and Paquier, A. (2016). Combined effects of bed friction and emergent cylinder drag in open channel flow. Environmental Fluid Mechanics 16 (6): 1173-1193. DOI 10.1007/s10652-016-9471-2.

3. El Kadi, K., Paquier, A. and Gay, A. (2008). OneDimensional numerical modelling of dam-break waves over movable beds: application to experimental and field cases. Environmental Fluid Mechanics 8: 169-198.

4. El Kadi, K., Paquier, A. and Mignot, E. (2009). Modelling flash flood propagation in urban areas using a two-dimensional numerical model. Natural Hazards 50: 433-460.

5. European Union (2007). Directive 2007/60/EC of the European Parliament and of the Council of 23 October 2007 on the assessment and management of flood risks. Official Journal of the European Union, L288: 27-34.

6. Lang, M., Arnaud, P., Carreau, J., Deaux, N., Dezileau, L., Garavaglia, F., Latapie, A., Neppel, L., Paquet, E., Renard, B., Soubeyroux, J.M., Terrier, B., Veysseire, J.M., Aubert, Y., Auffray, A., Borchi, F., Bernardara, P., Carre, J.C., Chambon, D., Cipriani, T., Delgado, J.L., Doumenc, H., Fantin, R., Jourdain, S., Kochanek, K., Paquier, A., Sauquet, E., Tramblay, Y. (2014). Results of Extraflo project (ANR 2009-2013) about the assessment of extreme rainfalls and floods. Houille Blanche - Revue Internationale de l'eau 2: 513 (in French).

7. Neal J. C., Odoni N. A., Trigg M. A., Freer J. E., Garcia-Pintado J., Mason D. C., Bates P. D. (2015). Efficient incorporation of channel cross-section geometry uncertainty into regional and global scale flood inundation models. Journal of Hydrology 529: 169-183, 2015. DOI 10.1016/j.jhydrol.2015.07.026 
8. Paquier, A. and Bazin, P.H. (2013). Coupling 1D and 2D Models for Simulating Floods: Definition of the Exchange Terms. Advances in Hydroinformatics, Simhydro 2012 - New frontiers of simulation: Chapter 11 , Springer.

9. Paquier, A. and Chiaverini, A. (2017). Modelling the 1910 flood in the Besancon Centre. Proceedings of 37th IAHR World Congress. Kuala Lumpur, Malaysia.

10. Paquier, A., Bazin, P.H. and El kadi Abderrezzak, K. (2019). Sensitivity of 2-D hydrodynamic modelling of urban floods to the forcing inputs: Lessons from two field cases. Urban Water Journal. DOI 10.1080/1573062X.2019.1669200.

11. Proust S., Bousmar D., Rivière N., Paquier A. and Zech Y. (2009). Non-uniform flow in compound channel: a 1D-method for assessing water level and discharge distribution. Water Resources Research 45 (W12411): 1-16. 